\title{
Brasileiros ilustres no tribunal da posteridade biografia, memória e experiência da história no Brasil oitocentista*
}

\section{Illustrious Brazilians in the tribunal of posterity biography, memory and history experience in the 19th century Brazil ${ }^{\star *}$}

\author{
MARIA DA GLÓRIA DE OLIVEIRA \\ Doutora em História Social/ UFRJ- Universidade Federal do Rio de Janeiro \\ Professora Adjunta/UFRRJ - Universidade Federal Rural do Rio de Janeiro \\ Instituto de Ciências Humanas e Sociais/Departamento de Letras e Ciências Sociais \\ BR 465, Km 7 - Seropédica/RJ-Brasil \\ CEP:23890-000 \\ mgloriaprof@gmail.com
}

RESUMO O artigo analisa a escrita de biografias como tarefa integrante do projeto historiográfico do Instituto Histórico e Geográfico Brasileiro ao longo do século XIX, com base nos discursos de Joaquim Manoel de Macedo e nos estudos biográficos de Joaquim Caetano Fernandes Pinheiro. Para os sócios da agremiação, a biografia deveria cumprir os propósitos de fixação da memória dos brasileiros ilustres, compartilhando com a escrita histórica das ambições de verdade e imparcialidade na representação do passado. Por outro lado, a evocação reiterada de um "tribunal da posteridade", em nome do qual se justificavam o trabalho de memória e a escrita biográfica, vinculava-se à experiência da história como foro de justiça e moralidade.

\footnotetext{
* Artigo recebido em: 18/08/2009. Aprovado em: 28/01/2010.

** Este artigo corresponde a uma versão modificada do capítulo 4 de minha tese de doutorado Escrever vidas, narrar a história. A biografia como problema historiográfico no Brasil oitocentista, defendida em março de 2009, no Programa de Pós-Graduação em História Social da UFRJ, com orientação do Prof. Manoel Luiz Salgado Guimarães
} 
Palavras-chave Historiografia, biografia, Instituto Histórico e Geográfico Brasileiro

ABSTRACT The article analyses biographic writings as a task of the Instituto Histórico e Geográfico Brasileiro historiographical project in the $19^{\text {th }}$ century Brazil, based on Joaquim Manoel de Macedo's speeches and Joaquim Caetano Fernandes Pinheiro's biographic studies. According to them, biography served to reinforce the memory of illustrious Brazilians by sharing ambitions of truth and impartiality on past representation with historic writings. Otherwise, the evocation of a "tribunal of posterity", justifying the work of memory and the biographic writing, was bonded with history experience as a force of justice and morality.

Keywords Historiography, biography, Instituto Histórico e Geográfico Brasileiro

A tarefa da história consistia em fixar a memória das vidas e feitos dos grandes homens. Tal convicção explicitou-se recorrentemente como argumento decisivo para a incorporação da escrita de biografias ao programa do Instituto Histórico e Geográfico Brasileiro no século XIX. A necessidade de arrancar do esquecimento os nomes dos brasileiros ilustres afinava-se com o ambicioso empenho da agremiação em coligir documentos para a elaboração da história nacional, tendo em vista as demandas políticas peculiares à consolidação do Estado monárquico no Segundo Reinado. ${ }^{1}$ Proposto pelo cônego Januário da Cunha Barbosa no discurso de fundação em 1838, o trabalho de "dar vida a beneméritos" adquiriu contornos concretos nas páginas da Revista Trimensal do Instituto com a seção de Biografias de Brasileiros Distintos por Letras, Armas, Virtudes, \&tc. A fecundidade do corpus biográfico estampado no periódico, longe de se reduzir a uma predileção literária exclusiva dos seus fundadores, renovou-se nas gerações subseqüentes, acompanhando o debate sobre como deveria ser escrita a história do Brasil. E, portanto, no processo de efetivação do projeto historiográfico do IHGB que os textos biográficos de seus sócios merecem ser examinados.

De imediato, é necessário assinalar que a importância atribuída à biografia como gênero nobre de escrita da história deixava de parecer

1 GUIMARÃES, Manoel Luiz Salgado. Nação e civilização nos trópicos: o Instituto Histórico e Geográfico Brasileiro e o projeto de uma História Nacional. Estudos Históricos, Rio de Janeiro, n.1, p.5-27, 1988; e MATTOS, IImar R. Tempo saquarema. A formação do estado imperial. 5ªed. São Paulo: Editora Hucitec, 2004. 
evidente para muitos historiadores no século XIX. ${ }^{2}$ No momento em que a história adquiria uma significação que transcendia os relatos históricos particulares para se converter em conceito coletivo singular como agente e sujeito de si mesma, que estatuto poderiam ter os relatos das vidas de indivíduos ilustres para o trabalho do historiador? ${ }^{3} \mathrm{O}$ abandono da ênfase no caráter exemplar dos grandes feitos individuais seria um dos traços da narrativa histórica oitocentista, da qual se passou a exigir não apenas conteúdo fidedigno, mas unidade épica, ou seja, uma maior capacidade de representação do curso dos acontecimentos como totalidade dotada de sentido. Em outras palavras, à pretensão de verdade que, desde sempre, fora atributo primordial do gênero historiográfico, combinar-se-ia uma ambição totalizante no plano narrativo.

Tais transformações acompanharam a disseminação de uma nova consciência histórica e a dissolução do topos da historia magistra vitae.$^{4} \mathrm{O}$ uso da fórmula herdada dos antigos correspondia à experiência da constância da natureza humana dentro de um espaço temporal contínuo e, por conseguinte, à concepção de história como fonte de exemplos edificantes e lições morais fornecidas pelo passado, com a utilidade de instruir o presente. Contudo, na perspectiva de um regime de historicidade em que a plausibilidade da história como disciplina fundar-se-ia cada vez mais na capacidade de compreender e explicar os processos históricos na sua singularidade, o lugar-comum acerca da função magisterial da historiografia perderia muito de seu sentido. ${ }^{5}$ Dentro de uma economia do tempo em que o futuro será a instância preponderante para a inteligibilidade do presente, o estatuto do relato biográfico, concebido como elaboração do imitável e do exemplar, tornar-se-ia problemático. Se, por um lado, a autonomização da ciência histórica exigiu que o historiador dilatasse o seu campo de observação, privilegiando o estudo das civilizações, dos povos e das instituições, por outro, deixava em aberto, ainda que implicitamente, o problema acerca do papel dos indivíduos no condicionamento do percurso inexorável da história, concebida como agente do destino humano e do progresso social. ${ }^{6}$

Não por acaso, as reflexões filosóficas do final do século XVIII, na mesma medida em que contribuem para a constituição da concepção de

2 DOSSE, François. Le pari biographique. Écrire une vie. Paris: La Découverte, 2005, p.185-194 et passim.

3 Ao longo do texto, utilizarei as expressões "vidas" e "biografias" como sinônimas, a despeito da precedência histórica do uso da primeira para designar o gênero biográfico (com bios dos gregos), e de sua larga vigência, pelo menos até meados do século XVIII, quando os termos biographie e biographe aparecem registrados em língua francesa no Dictionnaire de Trévoux (1721) com a definição de "história da vida de um indivíduo". MADELÉNAT, Daniel. La biographie. Paris: PUF, 1984, p.11-20.

4 KOSELLECK, Reinhart. Futuro passado. Contribuição à semântica dos tempos históricos. Rio de Janeiro: Contraponto/Editora PUC-Rio, 2006, p.41-44 et passim.

5 HARTOG, François. Regimes d'historicité. Presentisme et expériences du temps. Paris: Éditions du Seuil, 2003, p.117.

6 CATROGA, Fernando. O magistério da história e exemplaridade do grande homem. A biografia em Oliveira Martins. In: PÉRES JIMÉNEZ, A.; FERREIRA, J. Ribeiro e FIALHO, Maria do Céu. (ed.) O retrato literário e a biografia como estratégia de teorização política. Coimbra: Málaga, 2004, p.258. 
história como agente e sujeito de si mesma, também colocam em xeque a categoria antiga de herói, sobretudo a de varão ilustre plutarquiano, em nome de um novo personagem: o grande homem. A ênfase introduzida pela cultura das Luzes na noção de "mérito pessoal" reelaborou, sob outra perspectiva, um heroísmo de valor que seria inseparável de uma moral social. ${ }^{7}$ Assim, progressivamente laicizado, humanizado, "civilizado", o grande homem contrapunha-se ao herói guerreiro e passava a ser definido por suas qualidades pessoais e serviços prestados ao bem público e à humanidade. No caso emblemático do iluminismo francês, Jean-Claude Bonnet identificou em tal mudança de perspectiva um processo de "metamorfose da glória" que a dissociou da honra exclusiva, fundada em privilégios de nascimento e prerrogativas de pertencimento a um estamento social. ${ }^{8}$ Ao novo heroísmo das Luzes corresponde, enfim, uma nova relação com a temporalidade, advinda da experiência de ruptura irremediável do tormentoso período revolucionário. François Hartog entende que, na vida do grande homem, inscrevem-se as marcas da aceleração do tempo como uma espécie de prenúncio do futuro, na medida em que a noção remete à condição de perfectibilidade do gênero humano: "com os grandes homens, o tempo faria a sua entrada na história ou a história, ela mesma, tenderia a se transformar em tempo". ${ }^{9}$

Contudo, entre o paradigma heróico dos varões ilustres de Plutarco e os embates para a fixação dos méritos dos grandes homens na cultura das Luzes, os historiadores do oitocentos herdam o dilema que estará na base das suas relações ambíguas com o gênero biográfico. Nesse momento, embora uma "história do mundo" se impusesse como corolário das ambições da disciplina quanto à apreensão dos fenômenos históricos em sua totalidade, será sob o horizonte instransponível da nação que se ordenará simbolicamente o passado, o presente e o futuro. A novidade radical estará na tessitura de uma narrativa da construção política nacional, ou seja, na escrita da história como conhecimento autorizado e compartilhado. ${ }^{10}$ Aos historiógrafos caberia, enfim, a tarefa de conciliar o novo interesse pela marcha das forças coletivas no tempo e a identificação dos seus protagonistas. $\mathrm{Na}$ medida em que esboçam essas narrativas, assumem o papel de grandes árbitros, aqueles que estabelecem a correlação entre as ações individuais e o destino nacional: são eles que, em nome da nação, designam e validam os seus heróis. O culto dos grandes homens no contexto oitocentista implicava, portanto, a nacionalização da figura do herói, ou seja, os varões

7 BONNET, Jean-Claude. Naissance du Panthéon. Essai sur le culte des grands hommes. Paris, Fayard, 1998, p.29.

8 BONNET, Jean-Claude. Naissance du Panthéon, p.9-13 e 32

9 HARTOG, François. Plutarque entre les Anciens et les Modernes. In: PLUTARQUE. Vies parellèles. Paris: Gallimard, 2001, p.46

10 FABRE, Daniel. L'atelier des héros. In: CENTILIVRES, Pierre; FABRE, Daniel; ZONABEND, Françoise (orgs.). La fabrique des héros. Paris: Éditions de la Mason des sciences de l'homme, 1998, p.272. 
distintos seriam eleitos, antes de tudo, como grandes patriotas, valorosos por terem escrito uma página gloriosa da biografia da nação. ${ }^{11}$

Tal perspectiva foi notadamente explicitada pelos letrados do Instituto Histórico e Geográfico Brasileiro desde o momento de formulação de seu projeto historiográfico. À luz das diretrizes enunciadas pelo cônego Cunha Barbosa, a escrita da história nacional desdobrava-se em múltiplas vias de realização, entre as quais estava a constituição de uma galeria de nomes dignos a serem memorizados por seus grandes feitos em prol da nação. A noção-chave para a formação do panteon brasileiro será a do grande homem das Luzes, identificado por personificar a excelência do homem comum, letrado, benfeitor da humanidade e, sobretudo dotado de virtudes excepcionais como servidor do Estado. A publicação em série das biografias desses personagens pelo Instituto sugere, portanto, que eles encarnam valores coletivos celebrados pela sociedade política do Segundo Reinado.

Ao contrário das complicadas panteonizações da França revolucionária, que sublinhava divisões em um contexto de derrocada da monarquia, a memória dos grandes homens no Brasil constituiu-se, segundo Armelle Enders, em "um amplo empreendimento de reconciliação das elites" e, desse modo, "os vultos nacionais recolhe[ria]m apenas as migalhas do culto dinástico no reinado de D. Pedro II". ${ }^{12}$ Mais do que um embate teórico quanto às noções de "herói" ou de "grande homem", o que se apresentava como problema de solução complexa para os letrados do IHGB era a eleição de nomes ilustres nascidos no período anterior a 1822 e, por conseguinte, a criação de uma linhagem de brasileiros notáveis desde os tempos coloniais. Um panteon nacional pressupunha a existência histórica do Brasil a partir de seu descobrimento, o que facultava a inclusão não somente daqueles aqui nascidos, mas também dos naturais de outras partes do Império português, cujos serviços prestados tivessem sido relevantes para a nação. Baseado nessa prerrogativa, Francisco Adolfo de Varnhagen justificaria a inscrição de João Fernandes Vieira, o "Castrioto lusitano", na seção de brasileiros distintos, com a seguinte advertência em nota de pé de página: "O Instituto publicará também as biographias de varões illustres, que posto não sejam brasileiros por nascimento, todavia o são por acções gloriosas, e por haverem passado grande parte de sua vida n'este paiz". ${ }^{13}$ A despeito da firme proposição do Visconde de Porto Seguro, a eleição dos

11 HARTOG, François. Plutarque entre les Anciens et les Modernes, p.41-42.

12 ENDERS, Armelle. O Plutarco Brasileiro. A produção dos vultos nacionais no segundo reinado. Estudos Históricos, Rio de Janeiro, p.41-61, 2000. Sobre o culto dos grandes homens e a instituição do Pantheon na França revolucionária ver BONNET, Jean-Claude. Le culte des grands hommes en France au XVIIIle siècle ou la défaite de la monarchie. MLN, French Issue, n.4, v.116, p.689-704, 2001.

13 Biographia dos Brasileiros Distinctos por Lettras, Armas, Virtudes, \&tc. José Fernandes Vieira (o Castrioto lusitano) Revista do IHGB, t.5, p.82, 1843. Embora não traga o nome de Varnhagen indicado ao final do texto, a sua autoria é confirmada em LESSA, Clado Ribeiro de. Colaboração de Varnhagen no O Panorama. Revista do IHGB, t.193, p.106, 1946. 
personagens dignos de distinção no panteon do IHGB permaneceria longe de uma solução consensual, constituindo-se em uma espécie de sintoma do processo social mais amplo de conformação simbólica da nação e, sobretudo do equacionamento das diferentes peças do mosaico identitário em disputa na composição da nacionalidade brasileira. ${ }^{14}$

Se, por um lado, a aposta biográfica dos sócios do Instituto não pode ser dissociada das confluências políticas de tais embates, tampouco adquire sentido fora do contexto de disciplinarização da pesquisa histórica no decurso do oitocentos. Nesse momento, as narrativas acerca das origens dos estados nacionais deveriam se apresentar, antes de tudo, como um saber guarnecido de provas, cabendo àqueles que as elaboravam não somente oferecer o relato verdadeiro sobre os acontecimentos, mas também nomear os seus protagonistas. Os feitos dos homens ilustres não adquiririam conotação propriamente histórica senão quando fossem inscritos no processo de gênese nacional, o que significava que as suas ações deveriam ser não apenas narradas, mas documentadas. Tal preocupação está implícita na proposta de Cunha Barbosa e, de certa forma, articula-se a um propósito mais amplo. Nas palavras do cônego, tratava-se de erigir uma "bem ordenada galeria", na qual a "longa série de varões distintos" seria apresentada conforme "os tempos e os logares" das suas vidas. ${ }^{15} \mathrm{O}$ trabalho a ser empreendido consistia, antes de tudo, em uma operação de fixação da memória e combate ao esquecimento, o que revalidava o sentido original de "rito de recordação" enunciado no momento em que história nasceu como gênero de escrita, quando Heródoto declarou a preocupação em evitar que os feitos dos homens fossem apagados com o tempo. ${ }^{16}$ Por outro lado, a luta contra o apagamento das marcas do passado, empreendida pelos letrados brasileiros oitocentistas, corresponde a uma experiência temporal substancialmente distinta daquela dos antigos, como é possível perceber em outro discurso do secretário perpétuo:

Correm os tempos, e os acontecimentos, que uns a outros se sucedem, marcham tão rápidos, que o rastro de luz que aclara a geração presente, obliterar-se-hia na seguinte, se o gênio da Historia, coadjuvado pela Geographia e Chronologia, não tomasse a seu cargo fixal-os de modo que sirvam de instrucção aos povos de todas as idades. Elles se ligam sim em continuada cadêa por meio de relações, que algumas vezes só a intelligencia póde alcançar e restabelecer em seu estado de verdade e clareza; mas força é confessar, Srs., que milhares de circumstancias levam a nossa razão a desviar-se da verdadeira senda dos acontecimentos, augmentando assim as trevas com que a antiguidade desbota os factos que nos transmitte. A Historia é a memoria das nações, disse um sabio

14 JANCSÓ, István. Independência, independências. In: Independência: história e historiografia. São Paulo: Editora Hucitec/FAPESP, 2005, p.17-48.

15 BARBOSA, Januário da Cunha. Discurso. Revista do IHGB, t.1, p.16, 1839.

16 CATROGA, Fernando. Memória, história e historiografia. Coimbra: Quarteto, 2001, p.40-44. 
philologo; e de seu copioso deposito derivam ellas a necessaria instrucção, ou para se regularem no presente, ou para penetrarem o futuro, seguras em sua marcha. ${ }^{17}$

A consciência da aceleração do tempo vivido demandava da escrita da história não somente o registro de uma coleção de acontecimentos memoráveis, mas certa ordenação concatenada de sentido. Desse modo, longe de perder a sua eficácia persuasiva, renovava-se a convicção na antiga função da história como magistra vitae e, por conseguinte, na dimensão moralizadora de toda a experiência histórica. Contudo, a utilidade moral que dela se poderia extrair, longe de ser um dado espontâneo ou de fácil apreensão, subordinava-se a uma série de imperativos e interdições que então circunscreviam a prática dos historiadores.

\section{A verdade "sem partido" e o veto à história contemporânea}

O elogio acadêmico de um finado não póde ser uma biographia escripta com toda a severidade dos preceitos da historia, porque n'esta deve somente fallar a justiça e n'aquella podem desafogar-se a estima e a saudade; em uma a imparcialidade sentencia, no outro a gratidão paga um tributo; sentença e tributo porem que são igualmente generosos e nobres quando nascem da consciência e firmam-se na verdade. Os elogios justos, diz Voltaire, são um perfume que se reserva para embalsamar os mortos. ${ }^{18}$

As reflexões de Joaquim Manoel de Macedo reiteram uma antiga exigência dirigida ao trabalho do historiador, assinalando a diferença entre a biografia e o elogio dos mortos pelo uso dos preceitos mais rigorosos da história pela primeira. Desde Luciano de Samósata e Cícero, verdade e imparcialidade firmaram-se como traços distintivos ou, pelo menos, aspirações próprias da historiografia. ${ }^{19}$ Ainda nas palavras do orador do Instituto, não era raro "ver-se disfarçada no panegyrico dos mortos a lisonja incensadora dos vivos", mas se tornava necessário não confundir "os louvores tecidos pelo calculo do lisongeiro" com "o elogio que firmando-se na verdade, é o cumprimento de um dever com honra". ${ }^{20}$ A despeito da limitada confiabilidade dos gêneros, o elogio fúnebre e a biografia não estariam vedados àqueles que também se dedicavam à pesquisa histórica, desde que as exigências de verdade fossem atendidas em todas essas tarefas. "No grande tribunal da história", concluiria Macedo, "os contemporâneos dos varões notáveis são apenas testemunhas, e o juiz é somente a posteridade". ${ }^{21}$

17 Relatório do Primeiro Secretário Perpétuo Januário da Cunha Barbosa. Suplemento da Revista do IHGB, t.5, p.4, 1843.

18 Discurso do orador Joaquim Manoel de Macedo. Revista do IHGB, t.26, p.925-926, 1863.

19 ZANGARA, Adriana. Voir l'histoire. Théories anciennes du récit historique. Paris: EHESS, 2007, p.165-166.

20 Discurso do orador Joaquim Manoel de Macedo, p.925.

21 Discurso do orador Joaquim Manoel de Macedo, p.926. 
Parece evidente que essas ponderações contêm mais do que lugarescomuns acerca da elaboração de discursos laudatórios aos consócios falecidos, incumbência principal do orador da agremiação. A notória convicção em um "tribunal da história" transformava biógrafos e historiadores em "testemunhas" de seu próprio tempo enquanto que, à posteridade, atribuía-se a condição de verdadeiro foro de justiça das ações dos homens. ${ }^{22}$ Isso não significava, porém, que no empenho de ordenar os materiais para a escrita da história e fixar a memória das vidas de brasileiros distintos, os próprios letrados deixassem de exercer a função de árbitros:

Escrever ou também preparar a historia de um povo é, como pensa com razão Courcelle Seneuil, exercer uma verdadeira magistratura política, e o Instituto Histórico e Geographico do Brazil, colligindo e registrando os acontecimentos do passado e da actualidade, enthesourando elementos para os livros do futuro, pode dizer-se e preparador de um processo grandioso, no qual serão juizes os historiadores da posteridade. ${ }^{23}$

Mesmo que os juízos da história fossem concebidos como imanentes aos fatos e, desse modo, despontassem como efeitos da marcha inexorável do tempo, como atenuar o fardo da parcialidade que pairava insidiosamente sob os escritos dos biógrafos e historiadores, não obstante a evocação da força eqüitativa da posteridade? Dentro do IHGB, a verdade histórica "sem partido" seria uma exigência em nome da qual se formulariam as objeções quanto à investigação dos acontecimentos do passado imediato. Interdições similares seriam extensivas às biografias de nomes célebres da atualidade. A recepção da coletânea biográfica editada pelo francês Sébastien Sisson, oferecida ao Instituto em 1859, serve de exemplo paradigmático do veto à história imediata, tacitamente compartilhado por muitos consócios. No comentário referente à Galeria dos Brasileiros Ilustres, ${ }^{24}$ Joaquim Caetano Fernandes Pinheiro assinalaria que, naquele momento, a obra não poderia ser considerada "a biographia severa e desapaixonada", capaz de julgar os protagonistas "do nosso grande drama político". ${ }^{25}$ Nem por isso o seu idealizador deixava de prestar serviço à história, "arrancando do esquecimento muitos factos que debalde um dia com afan se buscariam, reflectindo em suas paginas as varias cores da actualidade". ${ }^{26}$ Ao contrário da crítica endereçada ao empreendimento coletivo organizado por Sisson, nos esboços biográficos do sócio Marcondes

22 Sobre a posteridade elevada a "foro de justiça" e a metáfora da história como "tribunal" ver KOSELLECK, Reinhart. Histoire, droit et justice. In: L'expérience de l'histoire. Paris: Éditions Gallimard/Seuil, 1997, p.161-180 e KOSELLECK, Reinhart. historia/Historia. Madrid: Editorial Trotta, 2004, p.60-65.

23 Relatório do primeiro secretário Joaquim Manoel de Macedo. Revista do IHGB, t.19, p.92, 1856

24 SISSON, S. Galeria dos brasileiros illustres (os contemporaneos), retratos dos homens mais illutres do Brasil, na politica, sciencias e letras, desde a guerra da independencia até os nossos dias, copiados por S. A. SISSON, acompanhados das suas respectivas biographias. Publicado sob a protecção de S. M. o Imperador. Rio de Janeiro: Lithographia de A. S. SISSON, 1859-1861, 2 v.

25 Revista do IHGB, t.22, p.700, 1859.

26 Revista do IHGB, t.22, p.700, 1859. 
Homem de Mello, o cônego exaltaria precisamente a "severa imparcialidade e critério com que julga[ra] successos ainda mui recentes, e a equidade com que sobre as campas meio abertas, pronuncia[ra] o juízo da história". ${ }^{27}$

Os inconvenientes de emitir juízos sobre as "campas" abertas da história ou de biografar personagens que ainda viviam, não eram ignorados pelos autores que, a despeito de tais objeções, dedicavam-se a trabalhos do gênero. Os requisitos invocados por Fernandes Pinheiro - imparcialidade e eqüidade no tratamento dos acontecimentos recentes - também serviriam de parâmetros recorrentes para a avaliação dos escritos biográficos. Tais seriam os critérios evocados no parecer acerca do Elogio Historico-Biographico de José Bonifácio, oferecido ao Instituto em 1877, para a admissão de José Maria Latino Coelho (1825-1891), então secretário da Academia de Ciências de Lisboa, como sócio correspondente. No entendimento de Olegário Herculano de Aquino e Castro e José Tito Nabuco de Araújo, ao abordar a vida de um dos protagonistas da independência do Brasil, o autor português não se limitara a apresentar uma simples biografia, mas "a pagina brilhante da historia de duas nações irmãs, em uma quadra difficil e melindrosa, grave e complicada, escripta com a proficiência e imparcialidade do consciencioso historiador, que só tem na mente a justiça, por norte a verdade, e por objecto o facto que se propõe a narrar ou a esclarecer". ${ }^{28}$

Entre os acontecimentos da história recente do Império, a emancipação política brasileira teria as suas investigações continuamente postergadas, não impedindo, porém, que a preocupação com o assunto se mantivesse constante entre os associados do Instituto. Lúcia Guimarães chama a atenção para o absenteísmo dos sócios no tocante ao tema da independência nos anos iniciais da agremiação, tomando como exemplo a tentativa malograda de instalação de uma comissão destinada a esclarecer os episódios de 1822. ${ }^{29}$ Poder-se-ia acrescentar que o tempo presente e, nesse caso, a história imediata do Império, funcionava muito mais como um motor daquele esforço de compreensão do passado, do que propriamente como objeto capaz de ser plenamente apreendido pela operação historiográfica. Não obstante a sua inserção à órbita do Estado monárquico, muitos integrantes do Instituto, ciosos em desempenhar a função de "artífices da nação", tinham também a preocupação em conferir às atividades da instituição um caráter menos partidário e mais "científico", ambicionando certa autonomia e neutralidade em relação ao contexto de disputas políticas no qual muitos estavam envolvidos. ${ }^{30}$

27 Revista do IHGB, t.25, p.716-717, 1862.

28 Parecer sobre o Elogio Histórico de José Bonifácio, por Olegário Herculano de Aquino e Castro e José Tito Nabuco de Araújo. Revista do IHGB, t.40, v.2, p.514, 1877

29 GUIMARÃES, Lúcia M. Paschoal. Da Escola Palatina ao Silogeu. Instituto Histórico e Geográfico Brasileiro (18891938). Rio de Janeiro: Museu da República, 2007, p.136.

30 CEZAR. L'écriture de l'histoire au Brésil au XIXe siècle. Essai sur une rhétorique de la nationalité. Le cas Varnhagen. Paris: EHESS, 2002, p.32 et passim (História, Tese de Doutorado). 
Com efeito, o adiamento da tarefa de elucidar os fatos da independência, especialmente para aquela primeira geração de acadêmicos, entre os quais despontavam alguns de seus principais articuladores, resultava de uma deliberada postura de prudência política frente à conjuntura de incertezas do período regencial. ${ }^{31}$ Além disso, a contumaz hesitação acerca do registro da história imediata da nação também seria justificada por meio de um argumento epistemológico, baseado na evocação do compromisso tácito do historiador com a verdade, a justiça e a imparcialidade. ${ }^{32}$

Ora, a despeito das biografias atenderem aos apelos mais prementes de certo dever de memória em relação aos beneméritos do passado nacional, tais prerrogativas não deixariam de orientar igualmente a sua elaboração. No parecer referido acima, o traço distintivo do escritor de história - "dizer a verdade, e pelo modo por que deve ser dita" - seria assinalado como critério decisivo para atestar o mérito do elogio biográfico de José Bonifácio, personagem cujo espectro controverso não chegou a vetar a sua inclusão na galeria de ilustres da Revista do Instituto. "Se a historia sem a verdade é apenas o romance, cumpre que ao dizêl-a, com inalterável firmeza e inteira segurança, possa ainda o escriptor guardar a propriedade do modo, a graciosidade da fórma e a conveniência do estylo, que asellam o caracter do perfeito historiador". ${ }^{33}$ Não era raro que as críticas ao estilo dos autores ocupassem espaço considerável na apreciação de trabalhos enviados ao Instituto, convertendo-se em quesito preponderante para o ajuizamento de seu valor historiográfico. É importante lembrar que, ao final da célebre dissertação Como se deve escrever a história do Brasil, Carl Phillip von Martius recomendava aos historiadores brasileiros "um estylo popular, posto que nobre", assinalando que a história não deveria ser escrita "em uma linguagem empolada (...) sobrecarregada de erudição ou de uma multidão de citações estéreis". Ao tomar como objeto uma nação "onde o povo ainda se acha[va] em desenvolvimento progressivo", a história do Brasil "deve[ria] parecer-se com um Épos", haveria que se aproximar de uma "epopéia popular" em que o seu autor imprimisse todo o seu patriotismo. ${ }^{34}$ Embora tais recomendações se apresentem como corolário da perspectiva pragmática com que o naturalista fundamentou o seu plano de uma história a serviço do Estado monárquico-constitucional, elas também indicam que a forma com que as narrativas históricas deveriam ser escritas não era questão secundária no oitocentos. Em decorrência disso, poder-se-ia afirmar que a exposição da verdade histórica seria concebida como inseparável de certa qualidade

31 GUIMARÃES, Lúcia M. Paschoal. Debaixo da imediata proteção de Sua Majestade Imperial: o Instituto Histórico e Geográfico Brasileiro (1838-1889). Revista do IHGB, Rio de Janeiro, n.388, p.571-572, jul./set.1995.

32 CEZAR, Temístocles. Presentismo, memória e poesia. Noções da escrita da história no Brasil oitocentista. In: PESAVENTO, Sandra J. (org.) Escrita, linguagem, objetos. Leituras de História Cultural. Bauru/São Paulo: Edusc, 2004, p.43-80.

33 Parecer sobre o Elogio Histórico de José Bonifácio, p.515.

34 MARTIUS, Carl P. von. Como se deve escrever a história do Brasil (1844). Revista do IHGB, p.204, 1953. 
formal que, longe de ser identificada a um mero revestimento ornamental do discurso historiográfico, convertia-se em exigência incontornável para a sua legitimidade "científica". Nesse sentido, as formas de narrar a história denotariam determinadas visões sobre o passado e, por conseguinte, as "verdades" que o historiador seria capaz ou não de captar. ${ }^{35}$

Para as narrativas de vida dos grandes personagens históricos, como já foi assinalado, impunham-se expectativas de veridicidade semelhantes. De acordo com Olegário Herculano e Nabuco de Araújo, no caso de um protagonista inconteste da emancipação brasileira era necessário, em nome da "justiça da historia", reconhecê-lo entre os "árbitros dos destinos do paiz" ${ }^{36}$ Atribuir a Bonifácio um lugar memorável na cena histórica nacional não significava, contudo, que fosse possível compor o quadro definitivo da história da "gloriosa revolução". Para os autores do parecer, permaneceria prematura qualquer tentativa de historiografar com verdade e imparcialidade os acontecimentos políticos de 1822.

\begin{abstract}
E se a severidade da critica ou a variedade do pensamento não permitte ainda que se fixe definitivamente a opinião que sobre os factos da independência deve ser formada; se é cedo para pronunciar-se a ultima palavra sobre assumptos que se prendem á nossa historia politica em tempos de tão agitadas comoções, seja-nos ao menos dado a nós, obreiros do porvir, juntar com desvelado esmero e accurada attenção todos os valiosos subsídios que a geração comtemporanea vai preparando para o soberbo monumento da historia da nossa pátria.A nós cabe a missão de honrar a memória dos grandes homens; á posteridade o encargo de julgal-os. ${ }^{37}$
\end{abstract}

A delimitação da tarefa prioritária dos "obreiros" do IHGB remetia, como já foi assinalado, à fórmula do ato fundador da historiografia. Percebe-se, contudo, que o propósito de combater a voragem do tempo reiterava-se não tanto pela operação da escrita, mas pela exortação ao trabalho prévio de arquivamento dos vestígios e testemunhos dos feitos dos grandes homens na marcha histórica da nação. A missão de acumular "valiosos subsídios" no presente para a elaboração de uma obra monumental no futuro implicava, além disso, experimentar o tempo não somente como produtor de esquecimento, mas como agente crucial na demarcação de uma perspectiva genuinamente histórica a servir de fundamento metodológico para as atividades do historiador. A distância temporal, antes tida como obstáculo para a apreensão dos tempos pretéritos, convertia-se, assim, em condição sine qua non para uma compreensão mais verdadeira da história, capaz de elevá-la ao estatuto de "ciência" investigativa do passado, objeto por excelência da operação historiográfica moderna. Isso

35 GAY, Peter. O estilo na história: Gibbon, Ranke, Macaulay, Burckhardt. São Paulo: Companhia das Letras, 1990, p.23.

36 Parecer sobre o Elogio Histórico de José Bonifácio, p.518.

37 Parecer sobre o Elogio Histórico de José Bonifácio, p.519-520. 
porque quanto mais imediatos os acontecimentos, menor a acuidade de sua inquirição pela "severidade da critica", daí o imperativo de renunciar à sua investigação para convertê-los em objetos de memória, tendo em vista a sua elaboração historiográfica na posteridade. Desse modo, a figura do historiador não mais deveria se confundir com a do cronista que relatava os fatos testemunhados, para assumir a função de guardião e crítico de testemunhos dos tempos pretéritos.

\section{O tribunal da posteridade}

A tarefa de honrar a memória dos grandes homens, empreendida como antídoto à ação do tempo, não era evocada sem que nela também estivesse implícito certo dever de justiça. Nos discursos dos sócios eminentes do Instituto, seria recorrente a analogia, tornada célebre por Jules Michelet, do papel do historiador com a de um magistrado encarregado do ofício de administrar o legado dos mortos, uma espécie de intermediário e intérprete de suas vozes junto à posteridade. ${ }^{38}$ Ninguém celebraria tal compromisso com mais clareza do que o orador Joaquim Manoel de Macedo:

O Instituto Historico e Geographico do Brasil reconhece que pela própria natureza dos fins que presidiram á sua organização, é um dos seus mais sérios e imprescriptiveis deveres o pagamento desse generoso tributo devido aos varões illustres que a morte vai roubando ao paiz: colligindo e publicando as biographias de cada um delles, vai recommendando os nomes e os feitos dos beneméritos ao tribunal da posteridade, que os deve julgar em ultima instancia, marcando o lugar que lhes compete na galeria da historia. ${ }^{39}$

O trabalho de memória não consistia tão somente na fixação de exemplos ou no estabelecimento de uma linhagem de ilustres a servir de espelho à nação, mas pressupunha uma relação de herança e dívida para com o passado. A escrita biográfica confundir-se-ia com a prestação de um tributo devido às vidas dos grandes homens, com a qual se perpetuariam as suas ações e seriam consignados os seus verdadeiros "lugares" na história. Haveria, portanto, uma vinculação entre os imperativos de memória e de justiça cujas implicações excederiam as questões epistemológicas de elaboração do conhecimento histórico para se inscreverem em uma problemática moral e ética mais ampla, relacionada às escolhas do historiador. ${ }^{40}$

Assim, a composição de biografias, justificada pelo imperativo de salvar do esquecimento os nomes valorosos do passado nacional, podia deman-

38 BARTHES, Roland. Michelet. São Paulo: Companhia das Letras, p.74, 1991; e HARTOG, François. Michelet, a história e a "verdadeira vida". Ágora, Santa Cruz do Sul/RS, n.1, v.11, p.13-19, 2005.

39 Discurso do orador. Revista do IHGB, t.22, p.706, 1859 (grifos meus).

40 Sobre as dimensões ético-políticas da memória e suas relações com a idéia de justiça ver RICOEUR, Paul. A memória, a história, o esquecimento. Campinas/SP: Editora Unicamp, 2007, p.99-104. 
dar, muitas vezes, uma firme opção pela crítica histórica como caminho privilegiado para a retificação da memória. De um modo bastante evidente, tal premissa marcaria as investigações de Joaquim Caetano Fernandes Pinheiro. Para o cônego, a defesa enfática do compromisso do historiador com a verdade e a imparcialidade, combinado ao pressuposto de um "tribunal da história", ao contrário de funcionarem como justificativas plausíveis para o adiamento da investigação dos acontecimentos do passado recente do Império, serviriam como argumentos propulsores para um estudo histórico sobre Revolução Pernambucana de 1817, intitulado sugestivamente de Luiz do Rego e a posteridade. ${ }^{41} \mathrm{Na}$ função de primeiro secretário do Instituto em 1861, ele comentaria o trabalho em seu relatório anual: "examinei, estreme de cor política, alheio às recriminações ou vindictas, e com a imparcialidade de que Tacito prezava-se guardar para com a memoria de Othon ou Vitellio, essa epoca de nós mais arredada pela transformação das idéas do que pelo lapso do tempo". ${ }^{42}$ Após compulsar "valiosos documentos" relativos ao episódio, Fernandes Pinheiro chegaria à convicção de que "injusta fora até aqui a historia para com um respeitável varão", o comandante português Luiz do Rego, enviado por D. João VI para debelar o movimento. ${ }^{43} \mathrm{O}$ que o cônego propunha era não somente a correção das inexatidões acerca dos fatos da revolução, mas a reabilitação daquele personagem histórico em nome de um pretenso sentido de justiça. Se, por um lado, a retificação da memória não dispensava procedimentos críticos específicos, tampouco podia prescindir do fator que se tornara coadjuvante ao método dos historiadores e das condições possíveis de elaboração historiográfica do passado: a própria temporalidade. Tal aspecto apareceria destacado já nas primeiras linhas do seu estudo:

razão tinham os antigos quando estabeleceram os juízos dos mortos; porque necessário é que desappareça o homem da superfície da terra para que se the faça justiça, para que com imparcialidade se julgue os seus actos. Pairam ainda por algum tempo em derredor dos túmulos o espectro das paixões, e releva que se haja elle ausentado para que sua final sentença profira a historia. ${ }^{44}$

A passagem é inequívoca quanto ao papel atribuído à posteridade e, por conseguinte, a própria história, como foro de justiça e moralidade. ${ }^{45}$ Ao contrário de destituí-lo de seus deveres, tal atribuição reforçaria o impreterível pacto do historiador com a verdade. Pois, na medida em que

41 Nas páginas da Revista, prevaleceu o silêncio sobre a revolução pernambucana até 1853, quando começaram a ser publicados documentos relativos ao movimento. Ver GUIMARÃES, Lúcia M. Paschoal. Da Escola Palatina ao Silogeu, p.118.

42 Relatório do primeiro secretário Cônego Joaquim Caetano Fernandes Pinheiro. Revista do IHGB, t.24, p.775, 1861.

43 Relatório do primeiro secretário Cônego Joaquim Caetano Fernandes Pinheiro, p.775 (grifos meus).

44 PINHEIRO, Joaquim Caetano Fernandes. Luis do Rego e a posteridade. Revista do IHGB, t.24, p.353, 1861

45 Sobre o uso recorrente da noção de "tribunal da posteridade" no IHGB das décadas iniciais do século XX. Ver GUIMARÃES, Lúcia M. Paschoal. Da Escola Palatina ao Silogeu, p.115-130. 
um julgamento mais definitivo dos homens era delegado ao "tribunal da posteridade", caberia aos historiadores a tarefa imediata, e não menos judiciosa, de estabelecer e inquirir diligentemente os testemunhos de modo a instituí-los como fontes dignas de credibilidade.

No estudo daquela "madrugadoura tentativa d'independencia", Fernandes Pinheiro questionava a inclusão do nome de Luiz do Rego entre os "algozes" das forças imperiais, elegendo como alvo de sua crítica a Historia da Revolução de Pernambuco em 1817 (1840), composta por um sócio correspondente, o padre Francisco Muniz Tavares, incluído entre os insurgentes. "Seguindo de perto o chronista da revolução pernambucana rectificaremos os equívocos que as reminiscências d'outra era, ou a carencia de documentos, Ihe fizeram commeter" ${ }^{46} \mathrm{~A}$ avaliação seria justificada por se tratar de uma história escrita por uma testemunha ocular dos acontecimentos narrados, "sob o mais apaixonado e inveridico prisma" e que, supostamente, poderia ser tomada "como puro manancial da verdade". ${ }^{47}$ Para contraditar o que considerava como opiniões equivocadas do padre pernambucano, o primeiro secretário não pouparia citações de outros testemunhos diretos daqueles episódios, além de acrescentar a transcrição integral de documentos oficiais do Império ao final texto: "não desejando sermos acreditados sob palavra documentaremos todas as proposições que emittirmos". ${ }^{48}$ Contudo, seria em torno da figura de Luiz do Rego que as suas divergências frente ao relato de Muniz Tavares mostrar-se-iam mais exacerbadas: "não podemos deixar de protestar contra a injustiça com que o tracta..." ${ }^{49}$ Diante da "infiel pintura" do oficial de armas traçada pelo cronista, que o descrevia como "adaptado para exterminar os pernambucanos", "auctorizado para cometter impune todos os attentados", Fernandes Pinheiro contrapunha a biografia composta por um literato coevo, para quem Rego destacava-se pela "brandura e espírito de conciliação". ${ }^{0}$ Igualmente passíveis de contestação eram as acusações quanto à atuação do comandante português no governo provisório da província e dos supostos excessos de autoridade cometidos no julgamento dos revoltosos. "Somos ainda aqui obrigados á presumir o leitor acerca dos devaneios poeticos do Sr. Moniz Tavares, cuja brilhante imaginação prejudica mais d'uma vez a verdade historica". ${ }^{51}$

Por meio de seu estudo sobre a revolução de 1817, Fernandes Pinheiro intentava "libertar a memória d'um honrado servidor do Estado", valendo-

46 PINHEIRO, Joaquim Caetano Fernandes. Luiz do Rego e a posteridade, p.354.

47 PINHEIRO, Joaquim Caetano Fernandes. Luiz do Rego e a posteridade, p.354 e 395

48 PINHEIRO, Joaquim Caetano Fernandes. Luiz do Rego e a posteridade, p.355.

49 PINHEIRO, Joaquim Caetano Fernandes. Luiz do Rego e a posteridade, p.375 (grifos meus).

50 PINHEIRO, Joaquim Caetano Fernandes. Luiz do Rego e a posteridade, p.376-377.

51 PINHEIRO, Joaquim Caetano Fernandes. Luiz do Rego e a posteridade, p.402. A obra de Muniz Tavares somente seria reabilitada em seu valor historiográfico durante as comemorações do centenário da revolução pernambucana, quando foi reeditada, com a revisão e as anotações críticas de Manoel de Oliveira Lima. Ver GUIMARÃES, Lúcia M. Paschoal. Da Escola Palatina ao Silogeu, p.119. 
se da distância que as transformações políticas posteriores ao movimento demarcavam frente ao quadro de circunstâncias daquela "chimerica republica" dos tempos coloniais. Entre aquele episódio e o momento em que se propunha a abordá-lo por meio de novos documentos e testemunhos, existiria, segundo o cônego, um lapso menor de tempo do que de idéias, o que favorecia uma reconstituição mais verdadeira dos acontecimentos comparada àquela do cronista revoltoso a quem criticava. Embora não assumisse uma postura de defesa dos insurgentes pernambucanos, Fernandes Pinheiro tampouco optou por estigmatizá-los, manifestando-se contrário à visão de Francisco Adolfo de Varnhagen acerca da proclamação do governo revolucionário: "Parece-nos o programma da republica de Platão, que alguns utopistas pretendiam transplantar para as margens do Beberibe; não julgamol-a porém incongruente, desconchava e ridicula como a considerou o nosso douto e respeitável collega o Sr. Varnhagen, a quem pedimos vênia para discordar de sua opinião". ${ }^{52}$

No mesmo ano em que anunciava o estudo histórico acerca da revolução de 1817, o primeiro secretário também oferecia para publicação na seção de brasileiros ilustres da Revista um esboço biográfico do padre Luiz Gonçalves dos Santos, personagem de reputação não menos controversa, cuja atuação fora notória nos episódios de 1822. "Bosquejando a vida do Athanasio fluminense, procurei tornar bem salientes as virtudes em que se extremava, e, sem dissimular que por vezes excessiva era a manifestação do seu zelo, fiz justiça á pureza de suas intenções". ${ }^{53}$ Nas primeiras linhas da biografia, Fernandes Pinheiro posicionava-se veementemente contra o "marasmo moral" e o "gélido sopro de indifferença" que, segundo ele, predominavam em relação aos grandes nomes dos tempos da emancipação política: "quase nenhuma attenção prestamos ás glorias do passado. Aguardam suas estatuas os architectos da nossa independencia; esperam pelo brasilico pantheon os varões beneméritos que pela pátria se dedicaram". ${ }^{54}$ No contexto dos embates políticos que antecederam a emancipação, o biografado merecia figurar no panteon do IHGB pela coragem com que retrucara as provocações dirigidas ao Brasil pelos deputados das cortes e propagadas nos periódicos portugueses. Além dos serviços prestados a favor da independência, fora autor das Memórias para servirem á História do Reino do Brazil, publicadas em 1825 pela Imprensa Régia de Lisboa, que deveriam ser consideradas menos como obra histórica do que "vasto repertorio" para os estudos futuros desse período: "faltavam a Luiz Gonçalves dos Santos os dotes d'historiador; compillador infatigável, nunca

52 PINHEIRO, Joaquim Caetano Fernandes. Luis do Rego e a posteridade, p.367-368.

53 PINHEIRO, Joaquim Caetano Fernandes. Relatório, p.777 (grifos meus).

54 PINHEIRO, J. C. Fernandes. O cônego Luiz Gonçalves dos Santos. Revista do IHGB, t.25, p. 163, 1862 (grifos do autor). 
deveria passar de chronista". ${ }^{55}$ Seria, portanto, por sua condição de "cidadão benemérito" que Fernandes Pinheiro justificaria o lugar designado ao padre polemista no panteon de celebridades do Instituto: "Dezessete annos nos separam do illustre fluminense para quem já começou a posteridade: póde pois sobre seu tumulo sentar-se a justiça" ${ }^{56}$

Nos estudos de Joaquim Caetano Fernandes Pinheiro, assim como nos discursos de Joaquim Manoel de Macedo, citados anteriormente, permanece subjacente o dilema partilhado pelos historiadores modernos entre introduzir juízos em suas narrativas, de modo a acentuar o seu papel de guardiões da memória dos mortos, ou permitir que a história proferisse por si mesma os seus veredictos, como efeito de sua sucessão inexorável e contínua. Por um lado, com a reiterada evocação de um "tribunal da posteridade", transferia-se para o próprio decurso da história a prerrogativa ajuizadora da qual os historiadores do oitocentos desejavam se abster ou, em última instância, delegar aos seus sucessores. A expectativa não estava mais nas sentenças morais passíveis de serem extraídas das histórias particulares, mas na força moralizadora própria da história concebida como processo. ${ }^{57}$ Assim, a experiência da história como um tribunal parecia absolver o historiador das suspeitas de parcialidade, fazendo-o revestir de ambições "científicas" o antigo preceito retórico de "deixar falar por si mesma a verdade da história". ${ }^{58}$

No contexto de formação das identidades coletivas que marcou a cultura histórica do Brasil no século XIX, historiografia e biografia compartilharam não apenas os propósitos de fixação dos fatos e nomes memoráveis, de modo que eles espelhassem valores e expectativas político-sociais dirigidas à nação, mas também as ambições de verdade e fidedignidade na representação do passado. Assim, ao buscarem inscrever a sociedade "surgida da cunhagem da moeda colonial" em um tempo propriamente histórico,59 os letrados brasileiros oitocentistas não dispensaram a articulação dessas duas modalidades de escrita na tessitura dos elos possíveis de ligação entre o presente, o passado e o futuro, indicando que, a despeito das novas exigências disciplinares, a história não precisaria renunciar terminantemente à antiga condição de magistra vitae em nome dos modernos axiomas de cientificidade.

55 PINHEIRO, J. C. Fernandes. O cônego Luiz Gonçalves dos Santos, p.168.

56 PINHEIRO, J. C. Fernandes. O cônego Luiz Gonçalves dos Santos, p.175.

57 KOSELLECK, Reinhart. história/Historia, p.62-63.

58 Uma vez formulada por Luciano de Samósata, a prescrição manteve larga vigência na modernidade, sendo reprisada na célebre fórmula "mostrar como as coisas efetivamente aconteceram", de Leopold von Ranke, ou em sua confissão não menos citada: "eu gostaria de poder apagar meu próprio eu, dando vez apenas às coisas que se manifestam por meio de forças poderosas". RANKE. Apud: KOSELLECK, Reinhart. Futuro passado, p.164-165.

59 MATTOS, IImar R. Tempo saquarema, p.296. 